\title{
A Fractal Approach to Calculate the Thermal Conductivity of Moist Soil
}

\section{Shanshan Cai}

Tengfei Cui

\author{
Boren Zheng
}

\author{
Pingfang Hu
}

\begin{abstract}
The ground heat exchanger (GHE) is a key component in the design of a GSHP system and the effective thermal conductivity is one of the most important parameters that determine the heat transfer underground. In this paper, the effect of particle sizes and distributions on the sand thermal conductivity were studied both experimentally and analytically. Fractal method was considered for simulating the thermal conductivity of both dry and moist, unsaturated sand. Seven types of dry sand samples and six types of moist, unsaturated sand were selected in the experiments and results showed that both porosity, fractal dimension and particle size ratio affect the sand thermal conductivity. Based on the fractal theory, the fractal models were applied to predict the sand thermal conductivity under both dry and wet conditions. By comparing to the experimental findings, the proposed model was able to predict the variation on the sand thermal conductivity. However, the contact thermal resistance and water distribution pattern are two key impacts on the soil behaviors and need to be further studied.
\end{abstract}

\section{INTRODUCTION}

The ground heat exchanger (GHE) is a key component in the design of a GSHP system and the soil thermal conductivity is one of the most important parameters that correlates to the amount of heat exchanged between the GHE and soil (Nam, et al. 2008; Schibuola and Tambani 2013). Thermal response test is normally used to determine the effective thermal conductivity of soil on site (Sanner, et al. 2005; Signorelli, et al. 2007). It is usually found that the measured result from one site of the borehole deviates from the test result derived from the borehole located next to it. This may lead to large differences during real operation. Although there are several empirical values and correlations published on soil according to the experimental measurements, the values are treated as constant for different types of soil and the correlations are normally correlated with macroscopic parameters, such as porosity and moisture content (Abu-Hamdeh, et al. 2001; Hwang, et al. 2010; Vijdea, et al. 2014). This rough estimation may decrease the accuracy of model prediction. Therefore, it is necessary to correlate the thermal property of soil with the specific mesoscopic structures for better prediction of the heat transfer procedure in soil.

Soil is acknowledged as natural substance with fractal geometry (Katz and Thompson 1985; Thompson and Krohn 1987; Lehmann, et al. 2003). Fractal analysis is a useful tool to describe the natural structures with irregular component sizes and phase arrangements (Bartoli, et al. 1991; Adler and Thovert 1993; Perfect and Kay 1995). Developments in fractal geometry help lead to better understanding of material properties and apparently chaotic processes in nature (Perrier, et al. 1999; Perrier and Bird 2002; Lehmann, et al. 2003; Dathe and Thullner 2005). In this study, the effect of soil particle sizes, distributions and solid thermal conductivity on the soil thermal conductivity were studied both experimentally and theoretically. The simulation results were compared to the experimental findings from laboratory tests.

\footnotetext{
Shanshan Cai (shanshc@hust.edu.cn) is a lecturer of energy and power engineering at Huazhong University of Science and Technology, China. Tengfei Cui is a graduate research assistant and Boren Zheng is an undergraduate research assistant. Pingfang Hu is a professor of Environmental and Science Engineering at Huazhong University of Science and Technology, China.
} 


\section{EXPERIMENTAL METHOD}

\section{Preparation and characterization of sand samples \\ In order to check the impacts of particle sizes and distribution on the sand thermal conductivity, seven groups of sand samples with fractal characters were prepared according to Table 1 and the main parameters were provided in}

Table 2. All of them satisfied the requirement for fractal geometry with $M\left(Z_{p}\right)=M Z_{p}^{-D}$ (Mandelbrot 1983). $M\left(Z_{p}\right)$ is the cumulative weight of the particles with the sizes no larger than $Z_{p}, Z_{p}$ represents the diameter of the particles, $M$ is the total weight of the test sample and $D$ is the fractal dimension. It should be noted that according to ASTM D653-14, sand is defined as particles of rock that will pass the No. 4 [4.75 mm/0.19 in.] U.S. standard sieve and be retained on the No. 200 [75 $\mu \mathrm{m} / 0.003$ in.] sieve. The particle size of our sample ranged from 0.045 to $5 \mathrm{~mm}$ (0.002 to 0.197 in.), and the dominant components of our samples are quartz and feldspar. Therefore, our samples belong to "sand" samples.

Table 1. Particle Size and Weight Distribution of the Samples

\begin{tabular}{|c|c|c|c|c|c|c|c|}
\hline $\begin{array}{l}\text { Warticle } \\
\text { Size mm (in.) }\end{array}$ & 1 & 2 & 3 & 4 & 5 & 6 & 7 \\
\hline $0.045-0.1(0.002-0.004)$ & & 5.94 & & 53.41 & & & 20.85 \\
\hline $0.1-0.125(0.004-0.005)$ & & 1.33 & & 2.44 & & & 2.46 \\
\hline $0.125-0.15(0.005-0.006)$ & & 1.30 & & 2.07 & & & 2.23 \\
\hline $0.15-0.2(0.006-0.008)$ & & 2.53 & & 3.43 & & & 3.95 \\
\hline $0.2-0.7(0.008-0.028)$ & 17.04 & 23.17 & 67.49 & 17.47 & 67.41 & 37.42 & 25.68 \\
\hline $0.7-1.3(0.028-0.051)$ & 12.71 & 25.56 & 8.90 & 10.39 & 8.88 & 13.57 & 20.01 \\
\hline $1.3-1.6(0.051-0.063)$ & 6.11 & 12.30 & 3.24 & 3.79 & 3.24 & 5.58 & 8.22 \\
\hline $1.6-2.3(0.063-0.091)$ & 13.86 & 27.86 & 6.00 & 7.00 & 5.99 & 11.25 & 16.59 \\
\hline $2.3-2.6(0.091-0.102)$ & 5.80 & & 2.13 & & 2.12 & 4.29 & \\
\hline $2.6-3(0.102-0.118)$ & 7.63 & & 2.54 & & 2.54 & 5.35 & \\
\hline 3-4 (0.118-0.157) & 18.66 & & 5.34 & & 5.34 & 11.98 & \\
\hline $4-5(0.157-0.197)$ & 18.20 & & 4.37 & & 4.35 & 10.56 & \\
\hline
\end{tabular}

Table 2. Summary of the Main Parameters in Test Samples

\begin{tabular}{|c|c|c|c|c|c|}
\hline Group No. & $\begin{array}{c}\text { Total Weight } \\
\text { g(oz.) }\end{array}$ & $\begin{array}{c}\text { Density } \\
\mathrm{kg} / \mathrm{m}^{3}\left(\mathrm{lb} / \mathrm{ft}^{3}\right)\end{array}$ & Porosity ( - ) & Fractal Dimension ( - ) & $\mathrm{Zp}(\max ) / \mathrm{Zp}(\min )(-)$ \\
\hline 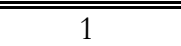 & $70(2.47)$ & $1707(106.55)$ & 0.34 & 2.1 & 25 \\
\hline 2 & $70(2.47)$ & $1707(106.55)$ & 0.34 & 2.1 & 51 \\
\hline 3 & $70(2.47)$ & $1707(106.55)$ & 0.34 & 2.8 & 25 \\
\hline 4 & $70(2.47)$ & $1707(106.55)$ & 0.36 & 2.8 & 51 \\
\hline 5 & $68(2.40)$ & $1659(103.56)$ & 0.36 & 2.8 & 25 \\
\hline 6 & $70(2.47)$ & $1707(106.55)$ & 0.33 & 2.5 & 25 \\
\hline 7 & $75(2.65)$ & $1829(114.17)$ & 0.29 & 2.5 & 51 \\
\hline
\end{tabular}

\section{Thermal conductivity measurement of dry and moist sand samples}

Considering that there would be moisture in the test samples, a hot wire transient method (ASTM C1113) is used for the thermal conductivity measurement (Assael, et al. 2002). Steady state methods usually require long time during testing and the results would be highly affected by moisture redistribution in the test samples. TC3000 from Xiatech Instrument were selected for thermal conductivity measurement. The range of the test instrument was from 0.001 to $10 \mathrm{~W} / \mathrm{m} \cdot \mathrm{K}\left(0.007\right.$ to $\left.69.3 \mathrm{Btu} \cdot \mathrm{in} /\left(\mathrm{hr} \cdot \mathrm{ft}^{2} \cdot{ }^{\circ} \mathrm{F}\right)\right)$ with the accuracy of $\pm 3 \%$. The test samples were placed in two test frames with dimensions of $50.5 \mathrm{~mm} \times 40.5 \mathrm{~mm} \times 20 \mathrm{~mm}(1.99 \mathrm{in} . \times 1.59 \mathrm{in} . \times 0.79 \mathrm{in}$.). The top and bottom surfaces of each frame were wrapped with plastic films to hold sand in position and prevent moisture evaporation happened during the measurement of moist samples. The sensor was placed in the middle between two frames during measurement. In order to evaluate the effect of two additional layers of plastic film on both sides of the sensor, calibration tests were applied by measuring two standard materials with films between the top and bottoms samples. 
The dry sand samples were provided by pre-conditioning in the oven at $105^{\circ} \mathrm{C}\left(221^{\circ} \mathrm{F}\right)$ for 24 hours, or until the two excessive measurement on the weight were within $0.1 \%$. The samples were cooled to room temperature before the measurement. The wet samples were prepared by adding water to sand in a beaker and mixed uniformly. During thermal conductivity measurement, each sample was tested at least three times with three groups of data ( 3 minutes apart from the last measurement) derived each time (at least nine data points in total). The test conditions were maintained at $25^{\circ} \mathrm{C}\left(77^{\circ} \mathrm{F}\right), 1 \mathrm{~atm}(14.7 \mathrm{psi})$.

\section{MODELLING METHOD}

\section{Approximation of the structure of sand by Sierpinski carpet}

Fractal method is applied in this study to simulate the variation on the sand thermal conductivity. The internal structure of sand is described by Sierpinski carpet model and the thermal resistance network is built according to the Sierpinski geometry based on the 1-D steady state heat transfer analysis (Ma, et al. 2003; Feng, et al. 2004; Feng, et al. 2007; Li, et al. 2012; Jin, et al. 2016). The basic Sierpinski geometry (Mandelbrot 1983) is shown in Figure 1. If the black square represents the solid particle, the model is considered as pore-mass fractal model, and if the black square represents the pore, the model should be treated as solid-mass fractal model. Sand can either be considered as solidor pore-mass fractal, however, the dimensions of the pores can hardly be determined and sand is treated as pore-mass fractal in the following model. The specifications of the Sierpinski geometry can be computed from Equations (1) to (2). Equation 1 (Mandelbrot 1983) shows the expression for fractal dimension $D$, which is determined by the side length of the Sierpinski carpet and the side length of the center matrix. It is different from dimensions of integer in Euclidean geometry and fractal dimension is often used to describe objects found in nature, such as rough surfaces, coastlines, soil, which are highly disordered and irregular. The porosity $\emptyset$ of Sierpinski carpet can be determined from Equation 2. Equation 3 represents the particle size ratio between the maximum and minimum particle sizes and the sizes are determined from Equation 4. The basic inputs, such as fractal dimension $(D)$, porosity $(\varnothing)$ and diameter of the particle $\left(Z_{p}\right)$ are determined from preliminary experiments. Different from most empirical correlations, porosity is no longer the only parameter that being considered on thermal conductivity. The particles sizes and distributions also play important roles in the thermal conductivity of porous sand.

$$
\begin{gathered}
\mathrm{D}=\frac{\ln \left(\mathrm{L}^{2}-\mathrm{C}^{2}\right)}{\ln \mathrm{L}} \\
Z_{p, \text { max }} / Z_{p, \text { min }}=1 /((L-C) / 2 L)^{n}
\end{gathered}
$$

$$
\begin{gathered}
\emptyset=\left[1-(\mathrm{C} / \mathrm{L})^{2}\right]^{\mathrm{n}+1} \\
Z_{p, \min }=C((L-C) / 2 L)^{n}, Z_{p, \max }=C
\end{gathered}
$$

Where $L(-)$ is the side length of the Sierpinski carpet, $C(-)$ is the side length of the center matrix, $\emptyset(-)$ is the porosity, $Z p(-)$ represents the particle diameter, and $n$ is the number of step.

Figure 2 shows the correlations between porosity $(\varnothing)$ and different parameters, side length of the center matrix $(C)$, fractal dimension $(D)$ and number of step $(n)$. Results showed that for the same porosity, there are different combinations of parameters $C, D$ and $n$. Therefore, the model for predicting sand thermal conductivity should not only depend on the porosity, but also include other parameters that would better describe the structure of sand. According to the input values provided in

Table 2, the other parameters $C, L$, and $n$ of each sample are determined from Equations (1) to (4) and the results are tabulated in Table 3 . 


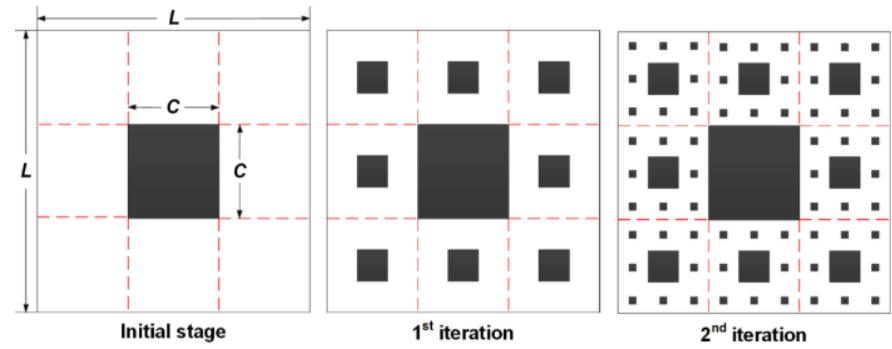

Figure 1 Sierpinksi carpet geometry for modeling sand (Jin, et al. 2016)

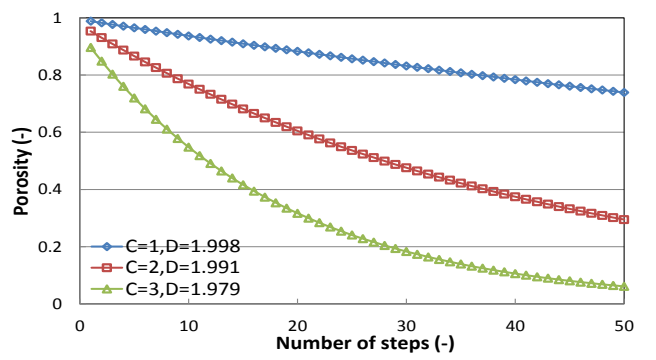

Figure 2 Correlations among different parameters

Table 3. Summary of the Main Parameters in Test Samples

\begin{tabular}{|c|c|c|c|c|c|c|}
\hline Group No. & $\emptyset$ & $\mathbf{D}$ & $\mathrm{Z} p(\max ) / \mathrm{Z}_{\mathrm{p}}(\min )$ & $\mathrm{C}$ & $\mathbf{L}$ & $\mathbf{n}$ \\
\hline 7 & 0.34 & 2.1 & 25 & 1.45 & 0.77 & 2.21 \\
\hline 2 & 0.34 & 2.1 & 51 & 1.36 & 0.67 & 2.87 \\
\hline 4 & 0.36 & 2.8 & 51 & 3.66 & 1.75 & 2.93 \\
\hline 6 & 0.33 & 2.5 & 51 & 2.01 & 1.09 & 2.18 \\
\hline 7 & 0.29 & 2.5 & 25 & 1.93 & 1.02 & 2.72 \\
\hline
\end{tabular}

\section{Two-phase fractal model for dry sand}

Under dry state, only solid and gas phase are considered in the model. According to the specific Sierpinski carpet geometry with appropriate values on $C$ and $L$, there is a corresponding thermal resistance network existed as shown in Figure 3 (iteration step $=0$ ). The thin, solid bar represents the contact thermal resistance between two particles. By assuming 1-D heat conduction, the thermal resistance network is composed of thermal resistances of solid and gas, plus the contact thermal resistance in a combined arrangement. The effective thermal resistance of each layer can be expressed as Equations (5) and (6). The contact thermal resistance, which represents by the value of $\tau$ can be neglected when $\tau<0.013 \mathrm{C} / \mathrm{L}$ ( $\mathrm{Ma}$, et al. 2003). Under this configuration, the difference caused by the contact thermal resistance is less than $1 \%$ and the thermal resistance $R_{2}$ can be rewritten in Equation (6).

$$
R_{1}=R_{3}=\frac{R_{11} R_{12}}{R_{11}+2 R_{12}}=\frac{L-C}{2 k_{a} L[(1-\tau)+\kappa \tau]}
$$

$$
R_{2}=\frac{k_{m}(C-t)+k_{a} t}{k_{a} k_{m}(L-C+t)+k_{m}{ }^{2}(C-t)} \approx \frac{C}{k_{a}[(L-C)+\kappa C]}
$$

Where $\tau=t / L$ and it represents the dimensionless contact thermal resistance, $\kappa=k_{m} / k_{a}$ which is the thermal conductivity ratio between solid and gas phase. By building the thermal resistance network, the dimensionless thermal conductivity can be expressed in different steps, as shown in Equations (7) to (8).

$$
\mathrm{K}^{(0)}=\frac{k^{(0)}}{k_{a}}=\left[\frac{1-\alpha}{\tau\left(\kappa^{(0)}-1\right)+1}+\frac{\alpha}{\alpha\left(\kappa^{(0)}-1\right)+1}\right]^{-1}
$$

$$
\mathrm{K}^{(\mathrm{n})}=\frac{\kappa^{(0)}}{\mathrm{K}^{(\mathrm{n}-1)}}=\mathrm{K}^{(\mathrm{n}-1)}\left[\frac{1-\alpha}{\tau\left(\kappa^{(\mathrm{n})}-1\right)+1}+\frac{\alpha}{\alpha\left(\kappa^{(\mathrm{n})}-1\right)+1}\right]^{-1}
$$




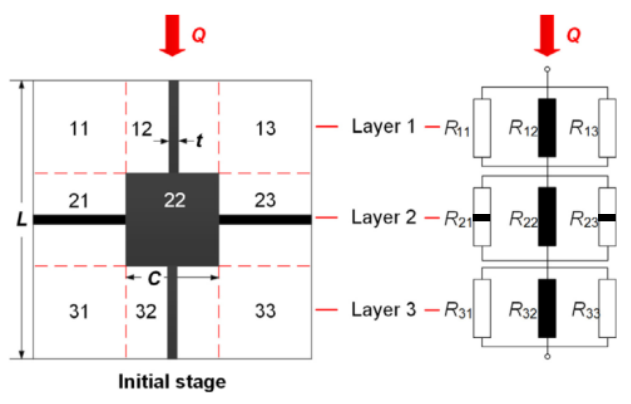

Figure 3 Thermal resistance network for Sierpinski carpet when step $=0$ (two phases) (Jin, et al. 2016)

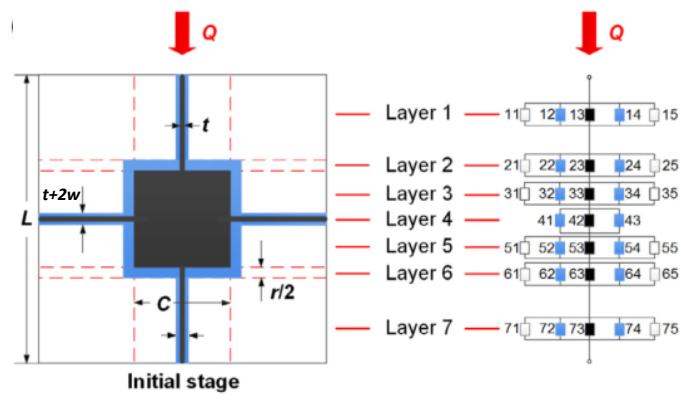

Figure 4 Thermal resistance network for Sierpinski carpet when step $=0$ (three phases) $($ Jin, et al. 2016)

\section{Three-phase fractal model for unsaturated, moist sand}

For moist sand, liquid phase is added in the two-phase model and fills in the cavities occupied by the gas phase. The liquid water cannot exist independently in the cavities under unsaturated condition, but covers the exterior surface of solid particles (water films) and accumulate around the intersection points (water bridges) (Ma, et al. 2003; Feng, et al. 2007; Jin, et al. 2016), as shown by the blue regions in Figure 4. The degree of moisture level can be expressed by the degree of saturation $S_{w}$ and $S_{w}=V_{w} / V$, where $V_{w}\left(m^{3}\right)$ and $V\left(m^{3}\right)$ represent the total volume of the liquid phase and total volume of the sample respectively. If assume the amount of liquid that covers the solid particles is $S_{f}$, and the amount of liquid that forms water bridges is $S_{b}$, then $S_{w}=S_{f}+S_{b}$. According to the Sierpinki model, the amount of liquid can be expressed as Equations (9) to (12)

$$
\begin{array}{ll}
S_{s}^{(n)}=\left[\left(\frac{\beta^{(n)}}{\alpha}+1\right)^{2}-1\right]\left[\left(\frac{1}{1-\alpha^{2}}\right)^{n+1}-1\right] & \text { (9) } \quad S_{b}^{(n)}=\frac{2 \omega^{(n)}\left(1-\alpha-\beta^{(n)}\right)}{\alpha^{2}}\left[\left(\frac{1}{1-\alpha^{2}}\right)^{n+1}-1\right] \\
\beta^{(\mathrm{n})}=\frac{r^{(n)}}{L}=\left[\frac{\mathrm{S}_{\mathrm{s}}^{(\mathrm{n})} \alpha^{2}}{\left[1 /\left(1-\alpha^{2}\right)^{\mathrm{n}+1}-1\right]}+\frac{1}{\alpha^{2}}\right]^{1 / 2}-\alpha & \text { (11) } \quad \omega^{(n)}=\frac{w^{(n)}}{L}=\frac{\mathrm{S}_{b}^{(\mathrm{n})} \alpha^{2}}{2\left[1 /\left(1-\alpha^{2}\right)^{\mathrm{n}+1}-1\right]\left(1-\alpha-\beta^{(n)}\right)}
\end{array}
$$

Where $\beta$ and $\omega$ are the dimensionless width of water films and water bridges, respectively. $\beta^{(\mathrm{n})}$ and $\omega^{(n)}$ represent the corresponding dimensionless forms at the $\mathrm{n}^{\text {th }}$ stage. Similar to the two-phase model, the dimensionless thermal conductivity model developed for unsaturated, moist phase can be simulated according to Equations (13) and (14).

$$
\begin{aligned}
& K^{(0)}=\left\{\frac{1-\beta^{(0)}-\alpha}{\kappa_{\mathrm{w}}{ }^{(0)} \omega^{(0)}+\kappa^{(0)} \tau+1-\omega^{(0)}-\tau}+\frac{\beta^{(0)}}{\left(\alpha+\beta^{(0)}-\tau\right) \kappa_{\mathrm{w}}\left({ }^{(0)}+\kappa^{(0)} \tau+1-\alpha-\beta^{(0)}\right.}+\frac{\alpha-\omega^{(0)}}{1-\alpha-\beta^{(0)}+\kappa_{\mathrm{w}}{ }^{(0)} \beta^{(0)}+\kappa^{(0)} \alpha}+\frac{\omega^{(0)}}{\kappa_{\mathrm{w}}^{(0)}(1-\alpha)+\kappa^{(0)} \alpha}\right\}^{-1} \\
& K^{(n)}=K^{(n-1)}\left\{\frac{1-\beta^{(n)}-\alpha}{\kappa_{w}^{(n)} \omega^{(n)}+\kappa^{(n)} \tau+1-\omega^{(n)}-\tau}+\frac{\beta^{(n)}}{\left(\alpha+\beta^{(n)}-\tau\right) \kappa_{w}^{(n)}+\kappa^{(n)} \tau+1-\alpha-\beta^{(n)}}+\frac{\alpha-\omega^{(n)}}{1-\alpha-\beta^{(n)}+\kappa_{w}(n) \beta^{(n)}+\kappa^{(n)} \alpha}+\frac{\omega^{(n)}}{\kappa_{w}^{(n)}(1-\alpha)+\kappa^{(n) \alpha}}\right\}^{-1}
\end{aligned}
$$

Where $\kappa_{w}$ is the thermal conductivity ratio of the water to dry air and $\kappa_{\mathrm{w}}{ }^{(0)}=k_{w} / k_{g}, \kappa_{\mathrm{w}}{ }^{(\mathrm{n})}=\kappa_{\mathrm{w}}{ }^{(0)} / K^{(n-1)}$. $\kappa$ is the dimensionless thermal conductivity ratio of the matrix to dry air and $\kappa^{(0)}=k_{m} / k_{g}, \kappa^{(\mathrm{n})}=\kappa_{m}{ }^{(0)} / K^{(n-1)}$.

\section{RESULTS AND DISCUSSION}

\section{Experimental results}

The test results of seven dry sand samples were listed in Table 4. Among test samples 1, 2 and 3, results showed that even with the same porosity, the sand thermal conductivity varied from $0.27-0.32 \mathrm{~W} / \mathrm{m}-\mathrm{K}$ (1.9-2.2 $\mathrm{Btu} \cdot \mathrm{in} /\left(\mathrm{hr} \cdot \mathrm{ft}^{2} \cdot{ }^{\circ} \mathrm{F}\right)$ ), around $17 \%$ of the average value. Both fractal dimension and the particle size ratio affect the sand thermal conductivity but it seems that the particle size ratio plays a more significant role. Larger differences on the sizes of the particles in the sand lead to higher thermal conductivity. This is because more non-uniform structure has higher possibility to create thermal paths in the heat flow direction. Porosity is another well-known parameter that causes the differences on the thermal conductivity of the samples. For example, if compares samples 3 and 5 which were prepared with the same values of fractal dimension and particle size ratio but different porosity, it was observed that sample 5 with higher porosity performed more conductive than the behavior of sample 3 with lower porosity. Higher porosity provides more vacancies for trapping air and increases the overall thermal resistance. Similar 
phenomenon was also observed between samples 6 and 7, however, it should be noted that the $22.2 \%$ increase on the thermal conductivity with regarding to the sample 6 was not only caused by the porosity, but also affected by the sizes of the particles in the samples. The thermal conductivity behaves proportional to the values of porosity, but inverse proportional to the particle size ratio, and this explains the phenomenon that observed on samples 4 and 5. Sample 4 had higher porosity when compare to sample 5 , but the thermal conductivity was around $8 \%$ higher, and this was due to the less uniform sizes in the sample 4.

Table 4. Summary of the Main Parameters in Test Samples

\begin{tabular}{lccccccc}
\hline Group No. & $\mathbf{1}$ & $\mathbf{2}$ & $\mathbf{3}$ & $\mathbf{4}$ & $\mathbf{5}$ & $\mathbf{6}$ & $\mathbf{7}$ \\
Thermal Conductivity & $0.28(1.9)$ & $0.32(2.2)$ & $0.27(1.9)$ & $0.26(1.8)$ & $0.24(1.7)$ & $0.27(1.9)$ & $0.33(2.3)$ \\
$\mathrm{W} / \mathrm{m}-\mathrm{K}\left(\mathrm{Btu} \cdot \mathrm{in} /\left(\mathrm{hr} \cdot \mathrm{ft}^{2} \cdot{ }^{\circ} \mathrm{F}\right)\right)$ & & & &
\end{tabular}

Six test samples, 1, 2, 4, 5, 6 and 7 were selected for the measurement of thermal conductivity with various amount of water. The sand thermal conductivity was observed fluctuating during wet test and the experimental findings on the variation of thermal conductivity ratio with moisture content (expressed as the degree of saturation) were provided in Figure 5. The thermal conductivity ratio represents the increasing on the sand thermal conductivity when compared to the dry values and saturation degree is the portion of water volume over the total vacancy in the sand. Certain amount of water was added uniformly in the sample to control the degree of saturation gradually increased up to $70 \%$. Six trend lines were applied to estimate the variation of thermal conductivity ratio of sand under different moisture levels. From Figure 5, it was observed that samples 4 and 7 showed faster increasing rate when compared to the other four samples. This phenomenon can be explained with the following three reasons. First, these two test samples were composed of particles at small sizes. During the experiment, it was found that liquid water existed in the cavities in two forms - the water bridge among different particles and the water film around the particles as shown in the picture taken by the optical microscope (Figure 6). Compared to large particles, the small ones have larger surface-to-volume ratio and have higher possibilities to form water bridges with the other particles located nearby. For the same thickness of water film and water bridge, water bridge leads to stronger effect on the overall thermal resistance than water film. Second, these two samples had higher particle size ratio when compared to most of the others. Similar to the explanation under dry conditions, higher particle size ratio would lead to higher possibility on the formation of thermal paths and increase the total thermal conductivity of sand. The effect of particle size ratio seems to vary with different fractal dimensions. For example, both samples 1 and 2 were prepared with fractal dimensions around 2.1 and it was observed that although the dry values of these two samples were different, the thermal conductivity ratio measured during wet tests were very similar. However, for test samples 3 and 4 with fractal dimensions around 2.8, the differences on the thermal conductivity ratio were higher than the samples 1 and 2 which were prepared with more uniform mixture of the particles at different sizes. Test samples 6 and 7 with fractal dimensions around 2.5 also showed large differences on the thermal conductivity ratio than the differences between samples 1 and 2. Therefore, the particle size ratio would affect the thermal conductivity of the sand and the effect behaves more significant in the less uniform samples. It should be noted besides particle size ratio, the porosity were different in samples 6 and 7 and this parameter should also be considered as one of the impact factors to explain the difference of the thermal conductivity ratio between these two samples. If the porosity of samples 6 and 7 are the same, the difference on the variation of thermal conductivity would between sand samples with higher fractal dimension (samples 3 and 4) and those with lower fractal dimension (samples 1 and 2). Therefore, porosity is the third reason that would explain the higher thermal conductivity ratio derived in some sand samples, especially for sample 4. The porosity of test sample 4 is 0.29 , which is the lowest among all the six test samples. For the same degree of saturation, the amount of water in sample 4 is more than the other samples with thicker water films and water bridges, which result in higher values of the thermal conductivity ratio. 


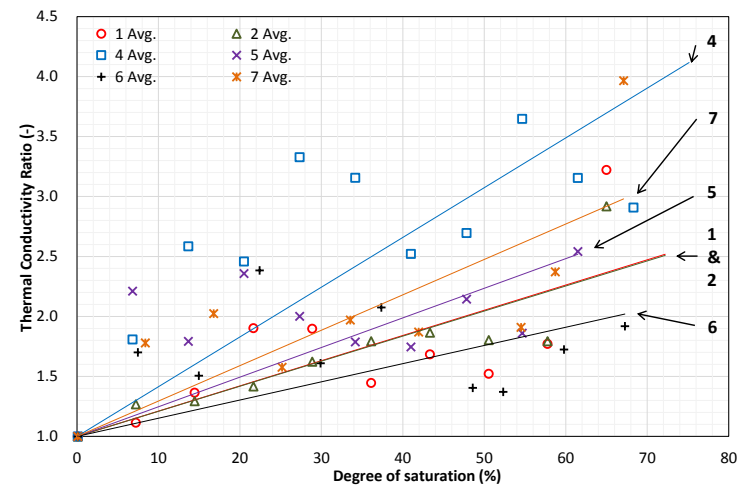

Figure 5 Thermal conductivity ratio of moist sand

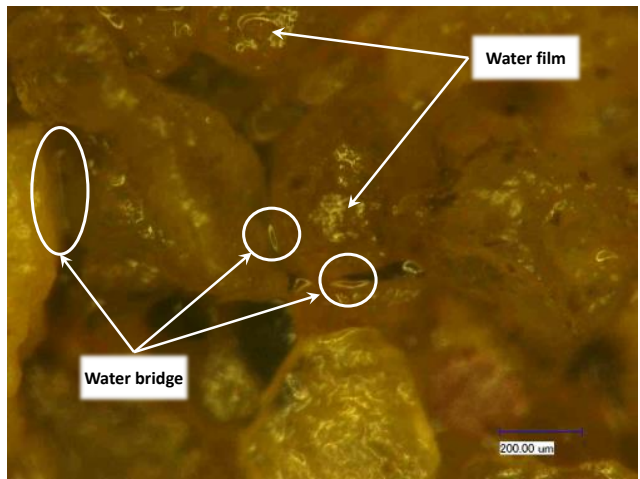

Figure 6 Optic photo of moist sand by optical microscope

\section{Modelling results}

The fractal model described in the previous section was used to simulate thermal conductivity of sand in both dry and wet conditions. According to the fractal dimensions, porosity and particle size ratio, parameters $C, L$ and $n$ can be determined from Equations (1) and (2) and tabulated in Table 3.

The simulated thermal conductivity of six test samples are provided in Table 5 . The thermal conductivity of air was selected at $0.026 \mathrm{~W} / \mathrm{m}-\mathrm{K}\left(0.2 \mathrm{Btu} \cdot \mathrm{in} /\left(\mathrm{hr} \cdot \mathrm{ft}^{2} \cdot{ }^{\circ} \mathrm{F}\right)\right)$. Actually, our sandstone samples were taken directly from the building yard, the dominant component is quartz and also contain some of feldspar. It's difficult to give the exact thermal conductivity values of the solid components, because quarzitic sandstones of our samples may have thermal conductivity quite different from that of the quartz crystals. Furthermore, quartz is highly anisotropic, with a thermal conductivity in the direction of the crystal axis twice higher than that in the direction perpendicular to the crystal axis (Woodside and Messmer 1961). Therefore, the value of $k_{s}$ was determined by using a geometric mean equation (Lu, et al. 2007), shown in Equation (15):

$$
k_{S}=k_{q s}^{\theta} k_{o}^{1-\theta}
$$

Where $\theta$ is the content of quarzitic sandstones $(\theta=0.8)$ with thermal conductivity $k_{q s}=2.5 \mathrm{~W} / \mathrm{m} \cdot \mathrm{K}(17.3$ $\mathrm{Btu} \cdot \mathrm{in} /\left(\mathrm{hr} \cdot \mathrm{ft}^{2} \cdot{ }^{\circ} \mathrm{F}\right)$, and other minerals, such as feldspar, thermal conductivity $k_{0}$ was taken as $1 \mathrm{~W} / \mathrm{m}-\mathrm{K}(6.9$ $\left.\mathrm{Btu} \cdot \mathrm{in} /\left(\mathrm{hr} \cdot \mathrm{ft}^{2} \cdot{ }^{\circ} \mathrm{F}\right)\right)$. In this work, a value for $k_{s}$ of $2 \mathrm{~W} / \mathrm{m}-\mathrm{K}\left(13.9 \mathrm{Btu} \cdot \mathrm{in} /\left(\mathrm{hr} \cdot \mathrm{ft}^{2} \cdot{ }^{\circ} \mathrm{F}\right)\right)$ at room temperature has been selected.

The thermal conductivity of dry sand could be determined according to Equation (8) and results showed that the simulated values matched experimental data within $1.7 \%$. It should be noted that the contact thermal resistance is a factor that correlates with the shape of particles, ways of contact and degree of compactness, all of which are difficult to be accurately measured. Rough estimation was given in Table 5 on the contact thermal resistance during the model calculation. A sensitivity analysis was applied on the contact thermal resistance to investigate its impact on the sand thermal conductivity and the findings were plotted in Figure 7. Results showed that if the contact thermal resistance varies by $\pm 20 \%$, the maximum difference on the sand thermal conductivity was within $\pm 5 \%$. The impact of the contact thermal resistance was more significant in the more uniform sand samples with lower fractal dimension and particle size ratio. The impacts of the other two parameters, porosity and particle size ratio, were also included in the sensitivity analysis as shown in Figure 8. The parameters considered in the baseline case was provided in the caption of the figure. It was observed that porosity and particle size ratio led to inverse impacts on the sand thermal conductivity and such phenomenon matched with the previous experimental findings. Compared to the particle size ratio, porosity played more significant role in the total value of sand thermal conductivity. A $\pm 20 \%$ variation on the sand porosity led to $\pm 20 \%$ difference on the sand thermal conductivity, but the same variation on the particle size 
ratio of the sand would only lead to differences around $\pm 5 \%$. The effect of solid thermal conductivity behaved similar to that of particle size and $\pm 20 \%$ variation would cause the effective thermal conductivity vary by $\pm 5 \%$.

Table 5. Experimental and simulated thermal conductivity of dry sand

\begin{tabular}{lccccccc}
\hline Samples & & 1 & 2 & 4 & 5 & 6 \\
\hline \hline Measured thermal & $\mathrm{W} / \mathrm{m}-\mathrm{K}$ & 0.279 & 0.316 & 0.256 & 0.24 & 0.271 & 0.333 \\
conductivity & $\left(\mathrm{Btu} \cdot \mathrm{in} /\left(\mathrm{hr} \cdot \mathrm{ft}^{2} \cdot{ }^{\circ} \mathrm{F}\right)\right)$ & $(1.93)$ & $(2.19)$ & $(1.77)$ & $(1.66)$ & $(1.88)$ & $(2.31)$ \\
Simulated thermal & $\mathrm{W} / \mathrm{m}-\mathrm{K}$ & 0.274 & 0.315 & 0.258 & 0.24 & 0.271 \\
$\begin{array}{l}\text { conductivity } \\
\text { Dimensionless contact }\end{array}$ & $\left(\mathrm{Btu} \cdot \mathrm{in} /\left(\mathrm{hr} \cdot \mathrm{ft}^{2} \cdot{ }^{\circ} \mathrm{F}\right)\right)$ & $(1.90)$ & $(2.18)$ & $(1.79)$ & $(1.66)$ & $(1.88)$ & $(2.30)$ \\
thermal resistance & - & 0.005 & 0.006 & 0 & 0.003 & 0.004 & 0.0003 \\
Difference & $\%$ & 1.7 & 0.3 & 0.7 & 0.08 & 0.08 & 0.2 \\
\hline
\end{tabular}

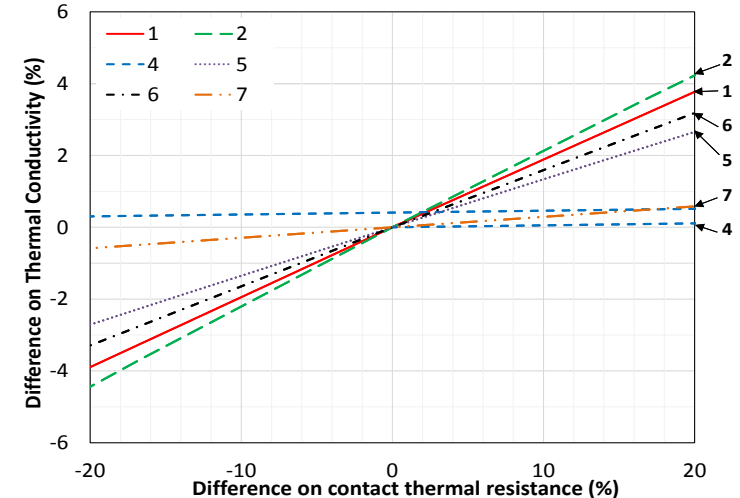

Figure 7 Sensitivity study of contact thermal resistance

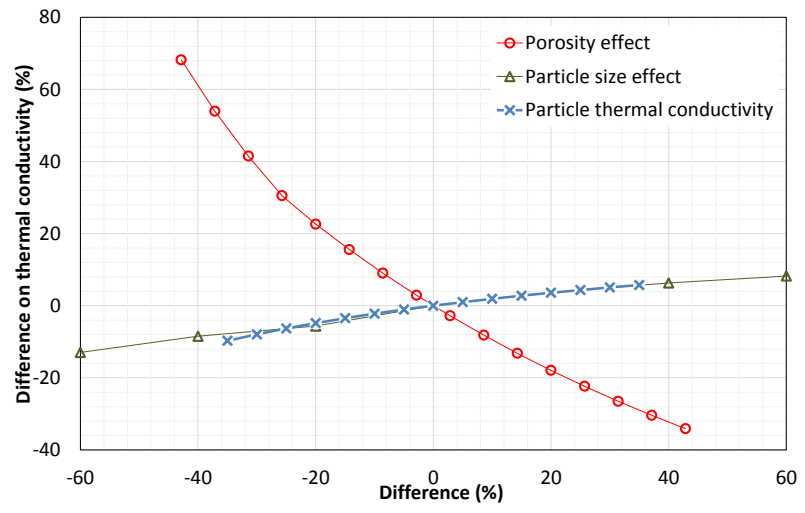

Figure 8 Sensitivity study of three main parameters (Baseline: $\emptyset=0.35, \mathrm{D}=2.8, \mathrm{Zp}(\max ) / \mathrm{Zp}(\min )=25, \mathrm{k}_{\mathrm{a}}=$ $0.026 \mathrm{~W} / \mathrm{m}-\mathrm{K}\left(0.2 \mathrm{Btu} \cdot \mathrm{in} /\left(\mathrm{hr} \cdot \mathrm{ft}^{2 \cdot}{ }^{\circ} \mathrm{F}\right)\right), \mathrm{k}_{\mathrm{m}}=2 \mathrm{~W} / \mathrm{m}-\mathrm{K}(13.9$ Btu $\cdot$ in $\left./\left(\mathrm{hr} \cdot \mathrm{ft}^{2 \cdot}{ }^{\circ} \mathrm{F}\right)\right)$

The thermal conductivity for moist, unsaturated sand was computed according to Equations (13) and (14). Figure 9 indicates the comparison between simulation results with the experimental findings on six types of sand samples. The simulation curves almost matched the experimental trends with certain water distribution pattern by adjusting the thickness of water film around the solid particles and water bridges among them. The parameters for the amount of water films $\left(S_{f}\right)$ formed around particles were provided in the caption of Figure 9, and the amount of water formed as water bridges among particles were present as $\left(1-S_{f}\right) \cdot S_{w}$. This amount of water correlated with the dimensionless thickness of water films, as well as water bridges, and higher thickness led to fast deterioration on the sand thermal conductivity. The amount of water film was in the range of $60 \%$ to $99 \%$ of the maximum saturated amount $\left(S_{w}\right)$. According to the previous findings, more water was covered around contact area and decreased the contact thermal resistance for the less uniform samples with large number of small particles. However, the water distribution pattern closely correlates with the particle shapes and size ratio and it would further affect the values on the sand thermal conductivity. It should be noted that soil-water retention curve would be very helpful to compare the amount of water retained in different types of samples with various porosity and particle size, and it will be considered in the further study on the modelling of moisture accumulation and distribution in the sand. Figure 10 provided the variation on the thermal conductivity with different water distribution structures. The moisture accumulation in the first pattern was assumed to form water bridge only when the moisture content below $30 \%$, and when the moisture content reached above 30\%, the moisture accumulate as water film around the sand particles. The second pattern was considered with constant number of water bridge and the thickness of water film was gradually increased. Results showed that the variations caused by these two different patterns were ranged from $-2.5 \%$ to $7 \%$ when compared to the baseline data derived on test sample 4. Therefore, it is important to determine the rules for moisture accumulation and distribution among particles in sand or soil and this work need to be further studied. 


\section{CONCLUSION}

This paper aims to study the impacts of particle sizes and distribution on the values of thermal conductivity of both dry and moist, unsaturated sand. The thermal conductivity of seven dry sand samples and six wet sand samples were tested according to the hot wire test device. Fractal method was proposed in this study to include the mesoscopic effect in the simulations of sand thermal conductivity. The main findings from the experimental and simulation results are summarized as follows. First, porosity, particle sizes and distributions affect the sand thermal conductivity. Between fractal dimension and the particle size ratio, it seems that the particle size ratio plays a more significant role. Larger differences on the sizes of the particles in the sand lead to higher values of thermal conductivity. Second, the thermal behavior of moist, unsaturated sand also correlates with porosity, particle sizes and uniformity. More uniform sand with smaller surface-to-volume ratio lead to much flatter variation on the thermal conductivity ratio. Third, fractal method is a promising technique to correlate sand thermal conductivity with mesoscopic geometry of sand and improve the accuracy of predicted values on the sand thermal conductivity. It seems that the simulation results from current fractal model generally matched with the experimental findings. However, the contact thermal resistance and water distribution patterns are still need to be further studied in the future work.

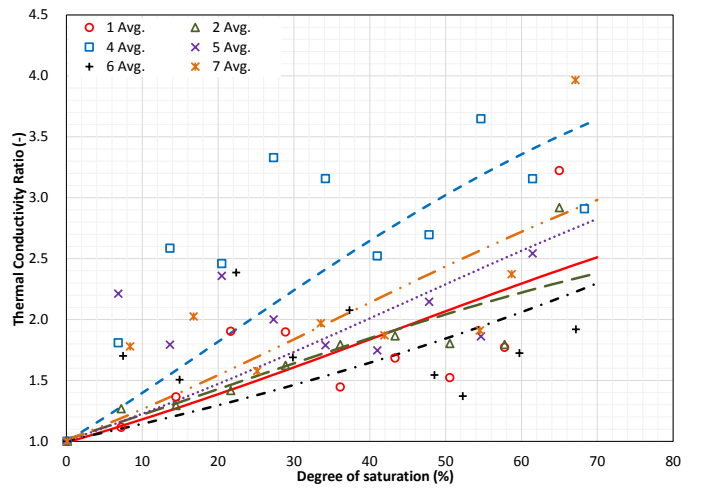

Figure 9 Comparison between the experimental and simulation results on the thermal conductivity ratio of unsaturated sand $\left(1: 0.9 \mathrm{~S}_{\mathrm{w}} ; 2: 0.85 \mathrm{~S}_{\mathrm{w}} ; 4: 0.6 \mathrm{~S}_{\mathrm{w}} ; 5: 0.9 \mathrm{~S}_{\mathrm{w}} ; 6\right.$ : $\left.0.99 \mathrm{~S}_{\mathrm{w}} ; 7: 0.9 \mathrm{~S}_{\mathrm{w}}\right)$

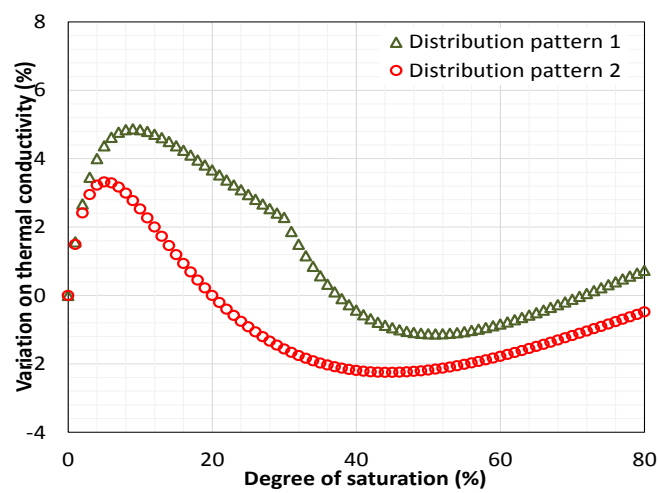

Figure 10 The effect of water distribution pattern on the thermal conductivity of unsaturated sand (Baseline: sample 4, $\mathrm{S}_{\mathrm{f}}=0.2 \mathrm{~S}_{\mathrm{w}}$; Pattern 1: Only $\mathrm{S}_{\mathrm{b}}$ increases when $0<\mathrm{S}_{\mathrm{w}}<$ $30 \%$, and only $\mathrm{S}_{\mathrm{f}}$ increases when $\mathrm{S}_{\mathrm{w}}>30 \%$; Pattern 2 : $\mathrm{S}_{\mathrm{f}}$ gradually increase in the range of $0<\mathrm{S}_{\mathrm{w}}<100 \%$;

\section{ACKNOWLEDGMENTS}

The authors gratefully acknowledge funding the support from Huazhong University of Science and Technology, Grant 2014QN182.

\section{NOMENCLATURE}

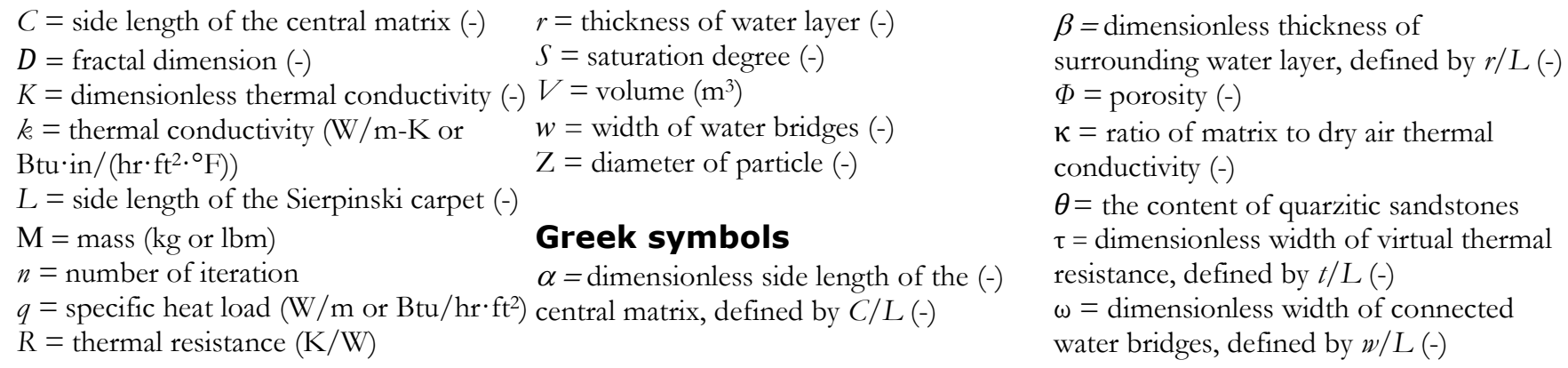




\section{Subscripts}

$a=$ air

$q s=$ quartzitic sandstones $o=$ other solid partciles

$b=$ connected water bridges

$f=$ surrounding water layer

$m=$ matrix $p=$ particle

$s=$ surface

$w=$ water

\section{REFERENCES}

Abu-Hamdeh, N. H.,A. I. Khdair and R. C. Reeder, et al. 2001. A comparison of two methods used to evaluate thermal conductivity for some soils. International Journal of Heat \& Mass Transfer 44 (5): 1073-1078.

Adler, P. M. and J. F. Thovert. 1993. Fractal porous media. Transport in Porous Media 13 (1): 41-78.

Assael, M. J.,M. Dix and K. Gialou, et al. 2002. Application of the Transient Hot-Wire Technique to the Measurement of the Thermal Conductivity of Solids. International Journal of Thermophysics 23 (3): 615-633.

ASTM. C1113(2013). Standard Test Method for Thermal Conductivity of Refractories by Hot Wire (Platinum Resistance Thermometer Technique) ASTM International.

Bartoli, F.,R. Philippy and Doirisse, M. 1991. Structure and self-similarity in silty and sandy soils: the fractal approach. Journal of Soil Science 42 (2): 167-185.

Dathe, A. and M. Thullner. 2005. The relationship between fractal properties of solid matrix and pore space in porous media. Geoderma 129 (34): 279-290.

Feng, Y.,B. Yu and M. Zou, et al. 2004. A generalized model for the effective thermal conductivity of porous media based on self-similarity. Journal of Physics D Applied Physics 37 (21): 3030-3040(11).

Feng, Y.,B. Yu and M. Zou, et al. 2007. A Generalized Model for the Effective Thermal Conductivity of Unsaturated Porous Media Based on Self-Similarity. Journal of Porous Media 10 (6): 551-568.

Feng, Y.,B. Yu and M. Zou, et al. 2007. A Generalized Model for the Effective Thermal Conductivity of Unsaturated Porous Media Based on Self-Similarity. Journal of Porous Media 10 (6): 551-568.

Hwang, S.,R. Ooka and Y. Nam. 2010. Evaluation of estimation method of ground properties for the ground source heat pump system. Renewable Energy 35 (9): 2123-2130.

Jin, H. Q.,X. L. Yao and L. W. Fan, et al. 2016. Experimental determination and fractal modeling of the effective thermal conductivity of autoclaved aerated concrete: Effects of moisture content. International Journal of Heat \& Mass Transfer 92: 589-602.

Katz, A. J. and A. H. Thompson. 1985. Fractal sandstone pores: Implications for conductivity and pore formation. Physical Review Letters 54 (12): 1325-1328.

Lehmann, P.,M. Stähli and A. Papritz, et al. 2003. A Fractal Approach to Model Soil Structure and to Calculate Thermal Conductivity of Soils. Transport in Porous Media 52 (3): 313-332.

Li, D. L.,J. W. Du and H. Song, et al. 2012. Measurement and modeling of the effective thermal conductivity for porous methane bydrate samples. Science China(Chemistry) 55 (3): 373-379.

Lu, S.,T. Ren and Y. Gong, et al. 2007. An Improved Model for Predicting Soil Thermal Conductivity from Water Content at Room Temperature. Soil Science Society of America Journal 71 (1): 8-14.

Ma, Y.,B. Yu and D. Zhang, et al. 2003. A self-similarity model for effective thermal conductivity of porous media. Journal of Physics D Applied Physics 36 (17): 2157-2164.

Mandelbrot, B. B. 1983. The fractal geometry of nature /Revised and enlarged edition/. New York W.h.freeman \& Co.p -1.

Nam, Y.,R. Ooka and S. Hwang. 2008. Development of a numerical model to predict heat exchange rates for a ground-source heat pump system. Energy \& Buildings 40 (12): 2133-2140.

Perfect, E. and B. D. Kay. 1995. Applications of fractals in soil and tillage research: a review. Soil \& Tillage Research 36 (1-2): 1-20.

Perrier, E. M. A. and N. R. A. Bird. 2002. Modelling soil fragmentation: the pore solid fractal approach. Soil \& Tillage Research 64 (1-2): 91-99.

Perrier, E.,N. Bird and M. Rieu. 1999. Generalizing the fractal model of soil structure: the pore-solid fractal approach. Geoderma 88 (3-4): 137-164.

Sanner, B.,G. Hellström and J. Spitler, et al. 2005. Thermal Response Test_Current Status and World-Wide Application.: 24-29.

Schibuola, L. and C. Tambani. 2013. Ground source heat pump performance in case of high humidity soil and yearly balanced heat transfer. Energy Conversion \& Management 76 (12): 956-970.

Signorelli, S.,S. Bassetti and D. Pahud, et al. 2007. Numerical evaluation of thermal response tests. Geothermics 36 (2): 141-166.

Thompson, A. H. and A. J. K. C. Krohn. 1987. "The Micro Geometry and Transport Properties of Sedimentary Rock,". Advances in Physics 36 (5): 625-694.

Vijdea, A. M.,C. Weindl and A. Cosac, et al. 2014. Estimating the thermal properties of soils and soft rocks for ground source heat pumps installation in Constanta county, Romania. Journal of Thermal Analysis \& Calorimetry 118 (2): 1135-1144.

Woodside, W. and J. H. Messmer. 1961. Thermal Conductivity of Porous Media. I. Unconsolidated Sands. Journal of Applied Physics 32 (9): 1688-1699. 